\title{
The Effect of Anticipatory Coarticulation of Bi-syllabic Words in Chinese
}

\author{
Maolin Wang \\ (College of Chinese Language and Culture / Overseas Chinese Education Research Institute, Jinan University, \\ Guangzhou, China)
}

\begin{abstract}
In this experiment, trans-segmental vowel-to-vowel anticipatory coarticulatory effect in Chinese is examined. The target words are in the form of ' $\mathrm{ei} \cdot \mathrm{bV}_{2}$ ' structure, and the subjects are eight native speakers of Mandarin Chinese. Vowel formants are analyzed at the offset, middle and onset points of the target vowel. Results show that trans-segmental coarticulatory effect does exist in Chinese, especially at the offset point of the target vowel, and coarticulatory effect does not extend to the middle or the offset points of the vowel.
\end{abstract}

Keywords: - Speech, coarticulation, vowel, formant

\section{INTRODUCTION}

People normally speak by producing a connected stream of sounds, and the usual situation is for speech segments to fit closely together with each other. It is shown that phonetics tends to look on utterance as a sequence of speech segments. In language it is found that speech segments have a strong effect on other segments which are adjacent to them. The process by which a speech segment is influenced by its neighbors is called coarticulation. Coarticulation refers to a state in which a conceptually isolated speech sound is affected by, and becomes more like, a foregoing or subsequent speech sound. Although it is clear that natural speech is coarticulated, its extent in various contexts has been hard to understand. To adequately describe the extent of coarticulation is a key factor in the development of computer models of speech production and perception [1]. It is revealed from researches on speech production that there are great differences among languages in the characteristics of coarticulation [2].

Öhman [3] studied the extent of coarticulatory effects in three languages, and found that, owing to vowel context, the $F_{2}$ values of vowels varied more in English and Swedish than in Russian. He argued that the coarticulatory differences came from the languages' consonant systems, stating that, in Russian, the contrastive palatalization restricts the tongue body in trans-consonantal coarticulation. Peoples have tried to examine how various factors affect the trans-consonantal vowel-to-vowel coarticulatory effect, and it has been displayed that the contrasts in the vowel system of a language may affect the $\mathrm{V}$-to- $\mathrm{V}$ coarticulation. Beddor et al. [4] carried out three experiments to investigate the ideas that $\mathrm{V}$-to- $\mathrm{V}$ coarticulatory mechanism is different in Shona and English. An experimental analysis of Shona and English tri-syllabic words shows that there are differences in the coarticulatory effect in the two languages of stressed and unstressed vowels on each other, and the relationship between the production and perception data shows that listeners are used to the coarticulatory patterns in their native languages.

If there is a large vowel system in a language, it tends to have weaker V-to-V coarticulatory effects than those with smaller vowel systems. In English, the coarticulatory effect is weak, compared to Shona, Swahili, where there are only five vowels in it vowel system [5]. Cho [6] investigated the relationship between the extent of vowel-to-vowel coarticulation and the prosodic boundary in speech utterances, and found at strong prosodic boundaries, the coariticulatory effect between adjacent vowels, and the influence on the adjacent vowels is not strong. He also examined the effect of duration on the coarticulatory effect, and it is shown that duration does not have much effect on the coarticulatory variation. The effect of accent and boundary is great, and the there is not great effect of duration on the V-to-V coarticulation. At prosodically strong boundary, the $\mathrm{V}$-to- $\mathrm{V}$ coarticulatory effect is reduced, which can be taken as another type of strengthening. There is a great effect of prosody on the coarticulatory pattern, and this is in fact part of the phonetic property of the hierarchical structure of prosody.

It is shown from research work on different languages that vowel-to-vowel coarticulation happens not only in the transition part of speech segments, but extending into the nuclear state section of the transconsonantal vowel both in physiological data [7-8] and in acoustic analysis data [9-10]. While there is a lot of findings about the existence of vowel-to-vowel coarticulatory effects, various factors have been explored which may affect the extent of these influences. For example, the effects of coarticulation may be restrained by intervocalic palatal and velar consonants, as in the pronunciation of these sounds, the application of the tongue 
body is in conflict with the pronunciation of vowels, so that vowel-to-vowel coarticulation is subsequently restricted $[7,11]$.

Earlier studies show that $\mathrm{V}$-to- $\mathrm{V}$ coarticulatory effect might be a comparatively local phenomenon [12], however, later research work has indicated that this is not always the case. Examples of long-distance coarticulatory effect, including those crossing two or more interposing speech segments have been discovered [13-14]. Magen [15] examined the [bVbəbVb] syllable sequences produced by four native English speakers and got results of coarticulatory effects between the first and last vowel, indicating that these effects can cross boundaries of foot and multiple syllable boundaries. later, Grosvald [16] investigated long-distance vowel-tovowel coarticulation in English, and found that, in a distance of at least three vowels, anticipatory V-to-V coarticulation can occur in natural speech discourse, and that even such long-distance effects can be perceptible to some listeners.

Some research work has been conducted on the coarticulation of speech segments in Chinese. Wu and Sun [17] investigated the acoustic coarticulatory models of voiceless fricatives, which are designed in the CVCV contexts with three peripheral vowels, /a, i, u/, being combined with the consonants in $\mathrm{C}_{1}$ and $\mathrm{C}_{2}$ positions. Acoustic data, including high energy frequencies and consonant durations of the lower margins, concentration bars, vowel formant values and the onset and offset transition patterns, are measured. It is found that there are three kinds of coarticulatory effects: homorganic ones, heterorganic and contiguous ones.

Yan [18] investigated the vowel formant patterns and the coarticulatory influence in the voiceless obstruent onset monosyllables, and it is shown that there is no effect of tones on the formant values of the vowels. However, the effect of aspiration is significant on the formant values at the onset point of the vowels. Chen [19] analyzed the inter-syllabic anticipatory coarticulatory effect in the CVCV syllable sequences, and found that there is no effect of articulation manner on the formant values. However, there is coarticulatory effect of $\mathrm{C}_{2}$ on $\mathrm{V}_{1}$, as well as $\mathrm{V}_{2}$ on $\mathrm{V}_{1}$. Sun [20] examined the coarticulatory effect of vowels in read speech discourse, and it is displayed that, as the speaking rate increases, the fluctuation of the vowel formant value is also magnified, as is shown in the obvious centralization of the vowel pattern. In speech of fast speed, the formant values of /i/ and $/ \mathrm{u} /$ are significantly different, owing to the frontness and the backness of the subsequent consonants. Besides, there is also the research work on the anticipatory coarticulatory effect in the V1\#C2V2 syllable sequences [21], and coarticulatory effect in the VCV syllable sequences [22].

The present experiment will examine the effect of trans-segmental anticipatory coarticulation in bisyllabic words in Chinese. In particular, it will try to investigate the subsequent questions. Does transconsonantal anticipatory coarticulatory effect happen in Chinese? What is the extent of the coarticulation in Chinese? Coarticulation may be classified into carry-over (left-to-right) or anticipatory (right-to-left) ones, and the present experiment will focus on anticipatory coarticulation.

\subsection{Speakers and stimuli}

\section{METHODOLOGY}

The subjects for this study were eight native speakers of Mandarin Chinese, four males and four females. The list of key words is comprised of 6 stimuli, rooted in three carrier structures of Chinese, each containing a word from a set of two key words. The key words are 'Bibi' and 'Biba', which are assumed to be names of two people. They are in the form of ' $\mathrm{bibV}_{2}$ ' structure, with /i/ as the target vowel, and $\mathrm{V}_{2}$ providing the 'alternating' vowel contexts, namely, the contexts of /i/ and /a/.

Labial / $\mathrm{b} /$ is chosen in order to reduce the influence of consonant articulation on lingual articulations [3]. Within the carrier structure, the key word item is located at the sentence initial position. One example is shown as follow,

Bibi de jiejie lai le.

Bibi's sister has come.

\subsection{Procedure and measurements}

The subjects were instructed to read the sentences three times, in random order for each repetition, in normal speed, so each speaker produced 18 tokens: 6 sentences $\times 3$ repetitions. In total, 144 tokens were acoustically examined (18 tokens $\times 8$ speakers).

The aim of this study is to investigate the extent of V-to-V coarticulation in the VCV syllable sequences, and vowel formants were measured. Formant values were obtained using the software of Praat [23], and the effect of trans-segmental coarticulation was analyzed by comparing the formant values of vowels in the key word at three points: the onset point, the middle point and the offset point. That is, formant values at the onset, middle and offset points of the target vowel /i/ were extracted, and the values at various vowel contexts were compared. As is mentioned in the foregoing subsection, there are two contexts for the preceding target vowel, /i/ and /a/. It is indicated that coarticulatory effect exists if significant difference exists between the 
formant values of the key vowel in the two contexts. On the contrary, there is no anticipatory coarticulatory effect if there is no significant difference. A repeated measures ANOVA was conducted for the comparison, and statistic analysis was done in SPSS.

Figure 1 presents the waveforms and formant contours of the two target words 'Bibi' (a) and 'Biba' (b). In the graphs, the vowel of the first syllable 'bi' is the key vowel, and the following syllables 'bi' and 'ba' offer the alternating vowel contexts. The formant values are extracted at the offset, middle and onset points of the vowel of the first syllable 'bi', which correspond to point A, B and C in the graphs. Comparison is conducted for formant values of the target values in the two vowel contexts at each of the three points. Take the offset point, point $\mathrm{A}$, as an example, since the contexts shown in graph (a) and graph (b) are different, if the formant values at point $\mathrm{A}$ under the two contexts are significantly different, it implys that there is an effect of coarticualtion at this point. In the present study, comparison will be done for both $F_{1}$ and $F_{2}$ values at each of the three points, the offset, middle and the onset point.

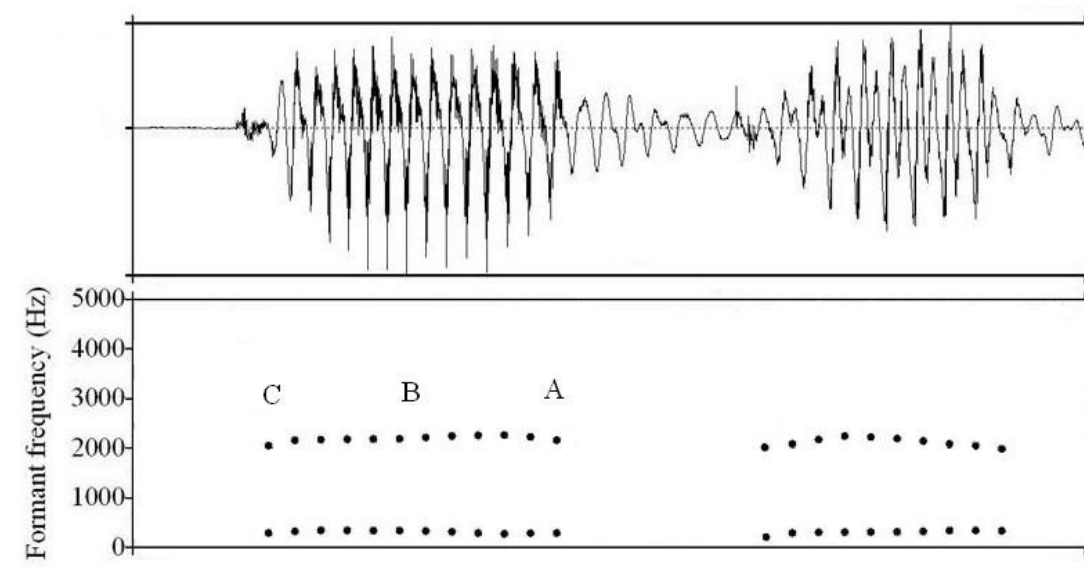

Bi

bi

Time (s)

a. The graph of 'Bibi'

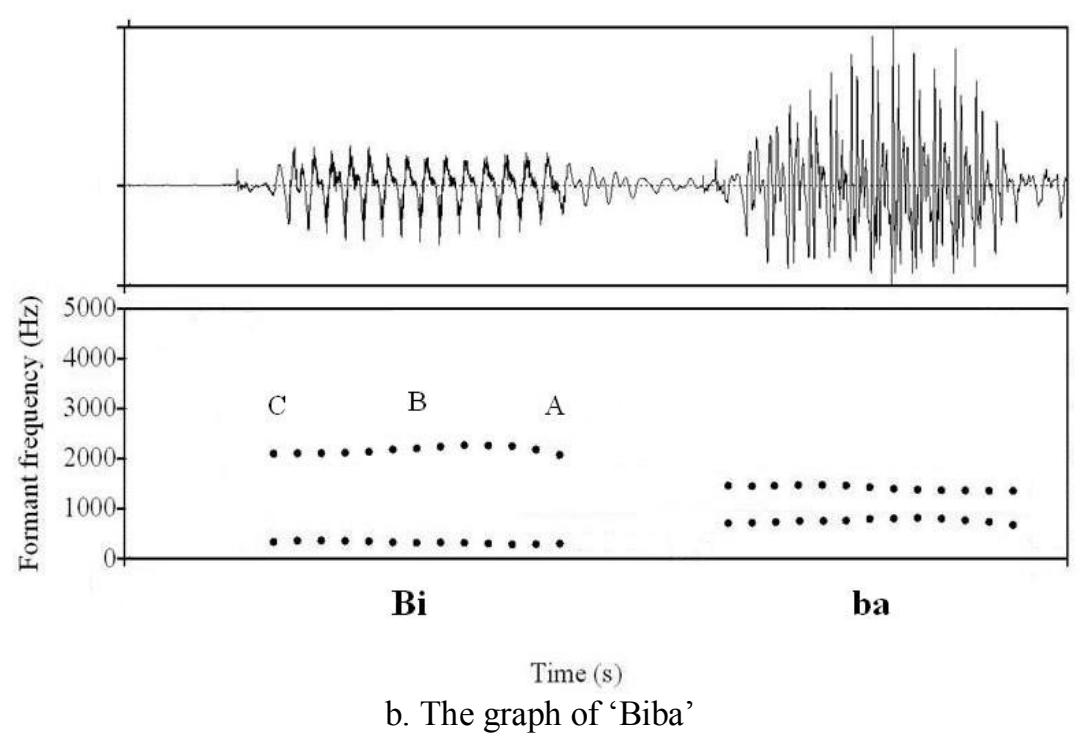

Figure 1 Waveforms and formant contours of the key words 'Bibi' (a) and 'Biba' (b)

\section{RESULT}

Figure 2 displays the mean $F_{1}\left(a\right.$ and $b$ ) and $F_{2}(c$ and $d$ ) values of the target vowel /i/ for male (a and $c$ ) and female ( $\mathrm{b}$ and d) speakers, in the contexts of $/ \mathrm{a} / \mathrm{and} / \mathrm{i} /$, measured at the offset, middle and onset points. One of the aims of this experiment is to examine the extent of the coarticulatory effect, so formant value is measured at three points, the offset, middle and the onset points of the target vowel. Analysis will be given in the following subsections. 


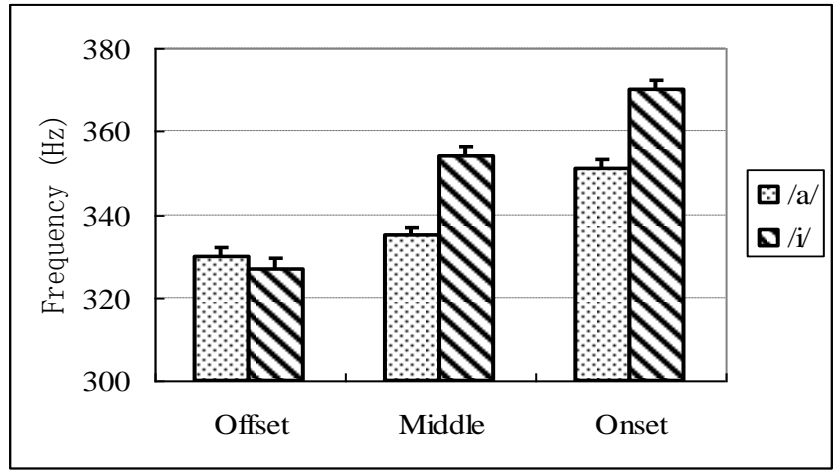

a. $F_{1}$ for male speakers

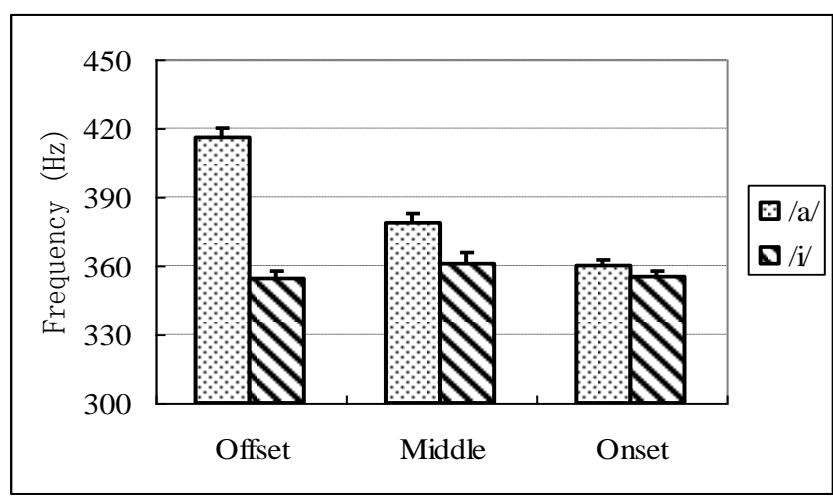

b. $F_{1}$ for female speakers

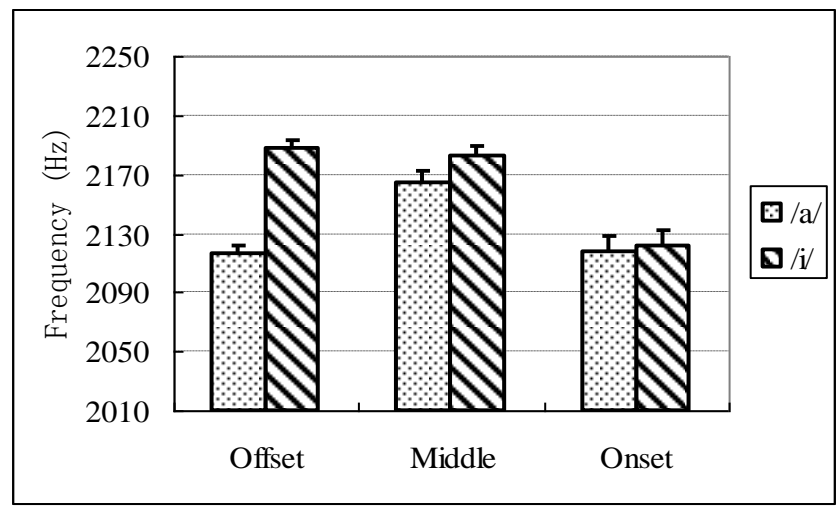

c. $\mathrm{F}_{2}$ for male speakers

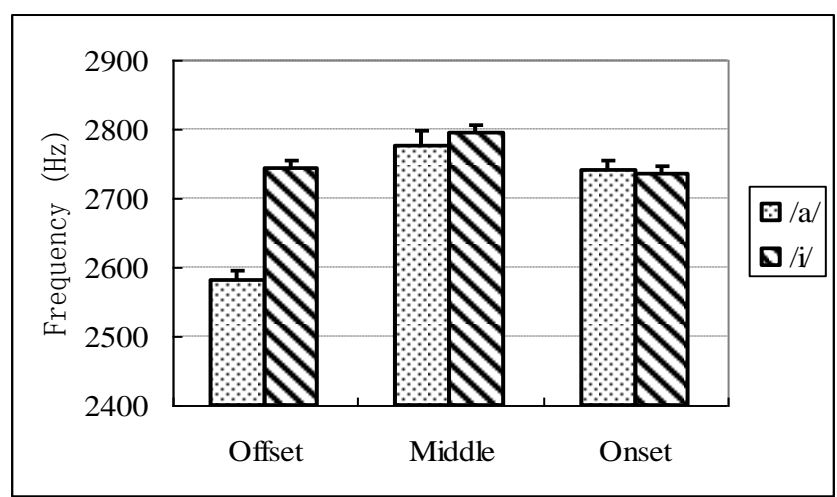

d. $F_{2}$ for female speakers

Figure $2 F_{1}\left(a\right.$ and $b$ ) and $F_{2}$ (c and d) values of the target vowel /a/for male (a and c) and female (b and d) speakers, in the contexts of /a/ and /i/, measured at the offset, middle and onset points 


\subsection{Offset point}

Results from a repeated measures ANOVA show that, at the offset point of the target vowel, with data of both male and female speakers pooled together, the effect of alternating vowel is significant for both $F_{1}$ and $F_{2}, F_{1}$ : $\mathrm{F}(1,71)=26.7, \mathrm{p}<0.001 ; \mathrm{F}_{2}: \mathrm{F}(1,71)=30.8, \mathrm{p}<0.001$. That is to say, coarticulatory effect exists at the offset point of the target vowel.

\subsection{Middle point}

Investigation shows that, at the middle point of the target vowel, the effect of alternating vowel is not significant for either $\mathrm{F}_{1}$ or $\mathrm{F}_{2}, \mathrm{~F}_{1}: \mathrm{F}(1,71)=0.013, \mathrm{p}=0.909 ; \mathrm{F}_{2}: \mathrm{F}(1,71)=2.702, \mathrm{p}=0.105$. Coarticulatory effect does not exist at the middle point.

\subsection{Onset point}

Coming to the onset point of the target vowel, it is shown that, similar to that at the middle point, the effect of changing vowel is not significant for either $F_{1}$ or $F_{2}, F_{1}: F(1,71)=2.48, p=0.072 ; F_{2}: F(1,71)=0.001, p=$ 0.972. Neither does coarticulatory effect exist at the onset point.

\section{DISCUSSION}

In observing the results presented in the foregoing section it is noted that, as far as the data in this experiment are concerned, trans-segmental coarticulatory effect does exist in Chinese, especially at the offset point of the target vowel. When formant values are analyzed at the offset point of the target vowel, it is shown that coarticulatory effect exists for both $\mathrm{F}_{1}$ and $\mathrm{F}_{2}$.

In this study, coarticulatory effect is observed at the offset, middle and onset points of the target vowel respectively, and it is displayed that, as far as anticipatory coarticulatory effect is concerned, the coarticulatory extent is strong at the offset point, and disappeared at the middle and onset points. To be specific, at the offset point of the target vowel, coarticulatory effect exists for both $F_{1}$ and $F_{2}$. However, when the middle and onset point of the target vowel is examined, it is revealed that coarticulatory effect does not exist. That is to say, for either $F_{1}$ or $F_{2}$, there is no coarticulatory effect. This result is caused by the 'distance effect': at the middle and offset points, the distance from the measured point of the vowel in the first syllable to the alternating vowels is close, and the effect is great; while at the middle and onset points, the distance gets farther, and the effect disappears.

In his research work on the investigation of the extent of vowel-to-vowel coarticulation for trisyllabic utterances in English, Magen [15] found that coarticulatory effects can, in some cases, extend beyond the boundaries that previous research had assumed. Coarticulatory effect can extend from one full vowel, through the schwa in the middle, into the midpoint of the next full vowel. Therefore, he proposed that foot can not define the domain over which coarticulatory effects apply. However, in the present study, it is shown that coarticulatory effect does not even extend to the middle point of the vowel. We speculate that this is because that Chinese is of different language typology from English.

It is known that one of the properties of language typology is the rhythm unit of the language. Languages have been classified as mora-timed, such as Japanese, stress-timed, like English and German, and syllable-timed, such as Chinese and French [25-26]. In accordance to this analysis, English is a stress-timed language, and the unstressed syllables in English are quite weak, so it is possible for coarticulatory effect to extend to the third syllable in English. However, Chinese is a syllable-timed language, in which syllables are rarely as weak as those in English. Compared to English, the degree of articulatory constraint (DAC) in Chinese is high. Therefore, the coarticulatory effect in Chinese is not as great as that in English.

\section{CONCLUSION}

This study investigated the vowel-to-vowel anticipatory coarticulation effect in bi-syllabic words in Chinese, and it is shown that trans-consonantal coarticulation exists in Chinese, especially at the offset point of the vowel of the first syllable. Because of the 'distance effect', coarticulatory effect is great at the offset point, and disappeared at the middle and onset points of the target vowel. In Chinese, coarticulatory effect is not as great as that in English, as the two languages are of different prosodic typology.

This research is, to some extent, significant for speech engineering. In speech synthesis, the effect of trans-consonantal coarticulatory effect must be taken into consideration, especially at the offset point of the target vowel. At the middle and onset points of the vowel, it is not necessary to care much about this effect, as in Chinese, coarticulatory effect does not extend to those points of the syllable. Therefore, this study may be helpful for speech engineering technology. 


\section{ACKNOWLEDGEMENTS}

This work was supported in part by the Social Science Research Project of Guangdong Province, Grant No. GD11CWW04, as well as the Humanity and Social Science Research Project for Colleges in Guangdong Province, Grand No. 11WYXM012.

\section{REFERENCES}

[1] W. F. Katz, "Anticipatory coarticulation and aphasia implications for phonetic theories", Journal of Phonetics, (28), pp. 313-334, 2000.

[2] S. Y. Manuel, "Cross-language studies: relating language-particular coarticulation patterns to other language-particular facts", in W. J. Hardcastle and N. Hewlett (eds), Coarticulation: theory, data and techniques, Cambridge University Press, Cambridge, U.K., pp. 179-198, 1999.

[3] S. E. G. Öhman, "Coarticulation in VCV utterances: spectrographic measurements," Journal of the Acoustical Society of America, Vol. 39, pp. 151-168, 1966.

[4] P. S. Beddor, J. D. Harnsberger and S. Lindemann, "Language-specific patterns of vowel-to-vowel coarticulation: acoustic structures and their perceptual correlates," Journal of Phonetics (30), pp. 591627, 2002.

[5] S.Y. Manuel and R. A. Krakow, "Universal and language particular aspects of vowel-to-vowel coarticulation," Haskins Laboratories Status Reports on Speech Research, SR-77/78, pp. 69-78, 1984.

[6] T. Cho, "Prosodically conditioned strengthening and vowel-to-vowel coarticulation in English," Journal of Phonetics, (32), pp. 141-176, 2004.

[7] D. Recasens, "Vowel-to-vowel coarticulation in Catalan VCV sequences," Journal of the Acoustical Society of America, 76, pp. 1624-1635, 1984.

[8] D. Recasens, "An acoustic analysis of V-to-C and V-to-V coarticulatory effects in Catalan and Spanish VCV sequences," Journal of Phonetics, 15, pp. 299-312, 1987.

[9] S. Y. Manuel, "The role of contrast in limiting vowel-to-vowel coarticulation in different languages," Journal of the Accoustical Society of America, 88, pp. 1286-1298, 1990.

[10] D. H. Whalen, "Coarticulation is largely planned," Journal of Phonetics, 18, pp.3-35, 1990.

[11] E. T. Purcell, "Formant frequency patterns in Russian VCV utterances," Journal of the Acoustical Society of America, 66, pp. 1691-1702, 1979.

[12] T. Gay, "Articulatory movements in VCV sequences," Journal of the Acoustical Society of America, (62), pp. 183-193, 1977.

[13] P. West, "The extent of coarticulation of English liquids: An acoustic and articulatory study," In Proceedings of the international conference of phonetic sciences, San Francisco, pp. 1901-1904, 1999.

[14] S. Heid and S. Hawkins, "An acoustical study of long-domain /r/ and /1/ coarticulation," In Proceedings of the fifth seminar on speech production: Models and data, Bavaria, Germany: Kloster Seeon, pp. 77-80, 2000.

[15] H. S. Magen, "The extent of vowel-to-vowel coarticulation in English," Journal of Phonetics, (25), pp. 187-205, 1997.

[16] M. Grosvald, "Interspeaker variation in the extent and perception of long-distance vowel-to-vowel coarticulation," Journal of Phonetics, (37), pp. 173-188, 2009.

[17] Z. Wu and G. Sun, "Acoustic coarticulatory patterns of voicelese fricatives in CVCV in Standard Chinese", Report on Phonetic Research, Institute of Linguistics, CASS, pp. 1-19, 1990.

[18] J. Yan, "A study of the vowel formant pattern and the coarticulation in the voiceless stop initial monosyllable of Standard Chinese", Report on Phonetic Research, Institute of Linguistics, CASS, pp. 30-54, 1990.

[19] X. Chen, "A study on the coarticulation of segments in Chinese, Chinese Linguistics", Zhongguo Yuwen, Vol. 5, pp. 345-350, 1997.

[20] G. Sun, "Vowel segmental coarticulation in read speech in Standard Chinese", Report on Phonetic Research, Institute of Linguistics, Chinese Academy of Social Sciences, 1998.

[21] Y. Li and J. Kong, "Anticipatory coarticulation in V1\#C2V2 sequences in standard Chinese," Journal of Tsinghua University, Vol. 51, No. 9, pp 1220-1225, 2011.

[22] M. Wang, W. Yan and Z. Xiong, "Coarticulatory effect in VCV sequences in Chinese," Journal of Tsinghua University, Vol. 51, No. 9, pp 1244-1248, 2011.

[23] P. Boersma, "Praat, a system for doing phonetics by computer", Glot International, 5:9/10, pp. 341-345, 2001.

[24] H. Bao, The physiological explanation of monophthongs in Chinese, Zhongguo Yuwen (2): pp. 117-127, 1984.

[25] K. L. Pike, The intonation of American English. Ann Arbor: University of Michigan Press, 1945.

[26] I. Lehiste, Suprasegmentals, Cambridge, MA: MIT Press, 1970. 